\title{
Investigation on Flexural Performance of RC Beams Flexurally Strengthened by Side-bonded CFRP Laminates
}

\author{
Guibing $\mathrm{Li}^{1, *}$, Yugang Guo ${ }^{2}$ and Xiaoyan $\mathrm{Sun}^{3}$ \\ ${ }^{I}$ College of Management Science and Engineering, Shandong Institute of Business and Technology, Yantai, 264005, China \\ ${ }^{2}$ International Business College, Shandong Institute of Business and Technology, Yantai, 264005, China \\ ${ }^{3}$ College of Civil Engineering and Architecture, Zhejiang University, Hangzhou, 310028, China
}

\begin{abstract}
It is an effective way to improve the flexural behavior of reinforced concrete (RC) members by externally bonded carbon fiber reinforcement polymer (CFRP) laminates on the soffit of the members. However, there is little investigation on flexural performance of RC beam flexurally strengthened by side-bonded FRP laminates. To investigate the flexural behavior of RC beams side-bonded CFRP laminates and the difference of RC beams strengthened by soffit-bonded and side-bonded CFRP laminates, a total of 8 CFRP-strengthened beams and 1 control beam were tested. The experimental results show that: 1) the first crack loads of RC beams strengthened by side-bonded CFRP laminates are much higher than that of RC beams strengthened by soffit-bonded CFRP laminates. The first crack loads of side-bonded CFRP laminates beams improved significantly; 2) Side-bonded and soffit-bonded CFRP laminates have almost the same effect on the flexural stiffness of RC beams strengthened with same quantity of CFRP laminates before tension rebar yielding. However, side-bonded CFRP laminates can affect crack width and crack pattern of the strengthened beams, and the pre-crack stage of RC beam by sidebonded CFRP laminates extended remarkably. 3) different to soffit-bonded CFRP laminates RC beams, side-bonded CFRP laminates cannot improve the first yielding and the ultimate load bearing capacity of RC beams.
\end{abstract}

Keywords: RC beam, side-bonded, CFRP, flexural performance.

\section{INTRODUCTION}

Externally bonded FRP laminates on the soffit of RC beams is an effective way in flexural strengthening. However, there is little investigation on flexural behavior of RC beam by side-bonded CFRP laminates. Zhang et al., [1] investigated the flexural behavior of four under-reinforced concrete beams strengthened by side-bonded CFRP laminates. Oehler et al., [2] and Mohamed Ali et al., [3] concluded that FRP side plated beams, in some situations, was a better option than FRP tension face plated beams as they can achieve higher strength and ductility.

To investigate the flexural behavior of side bonded CFRP laminates RC beams and the difference of flexural behavior between soffit-bonded and side-bonded CFRP laminates RC beams, this paper presents experimental study to investigate the flexural behavior of RC beams by side-bonded and soffit-bonded CFRP laminates.

\section{EXPERIMENTAL PROGRAM}

6 side-bonded CFRP sheets RC beams, 2 soffit-bonded beams, and 1 control beam were tested. Fig. (1) shows the dimension and reinforcement arrangement of specimen. The test set-up and instrumentation locations are shown in Fig. (2). According to the design provisions provided by

*Address correspondence to this author at the College of management science and engineering, Shandong Institute of Business and Technology, Yantai, 264005, China; Tel: +86-755-6903575;

E-mails: liguibing@zju.edu.cn, leegb@sina.com
CECS146-2003 [4], all strengthened beams were designed to be failed by flexural failure in order to investigate their flexural behavior. The test variables included number of ply of CFRP laminates, bonding configuration of CFRP laminates and anchor program of CFRP laminates at beamcolumn joint. As shown in Fig. (3a-c), two kinds of anchor programs were used to anchor CFRP laminates for the sidebonded beams, one is flexible anchor (denoted by F), and the other is rigid anchor (denoted by R); Fig. (3d) shows the anchorage of soffit-bonded CFRP laminate beams at the joint. The bonding configuration and amount of CFRP laminates are shown in Fig. (3e). Table 1 lists the CFRP sheets configuration of each specimen.

Ready-mixed concrete with cube compressive strength 55.8 MPa was used. The properties of CFRP laminate, with ultimate tensile strength $4150 \mathrm{MPa}$, Young's modulus 235 $\mathrm{GPa}$, and nominal thickness $0.111 \mathrm{~mm}$, were provided by the manufacturer. The ultimate tensile strength of tension rebar is $380 \mathrm{MPa}$, and its Young's modulus is $200 \mathrm{GPa}$.

\section{TEST RESULTS AND ITS ANALYSIS}

Table 2 summarizes the characteristic load and failure modes of all test beams. Figs (4 and 5) show the comparisons of load-deflection behaviors of side-bonding, soffit bonding and control beams. As the soffit bonding CFRP laminates beams, Side-bonding FRP laminates can also improve the flexural behavior of RC beams. However, it is obviously that the flexural behavior of the beams with side-bonding CFRP laminates is worse than that of the beams by soffit bonding, and the flexural behavior of the 


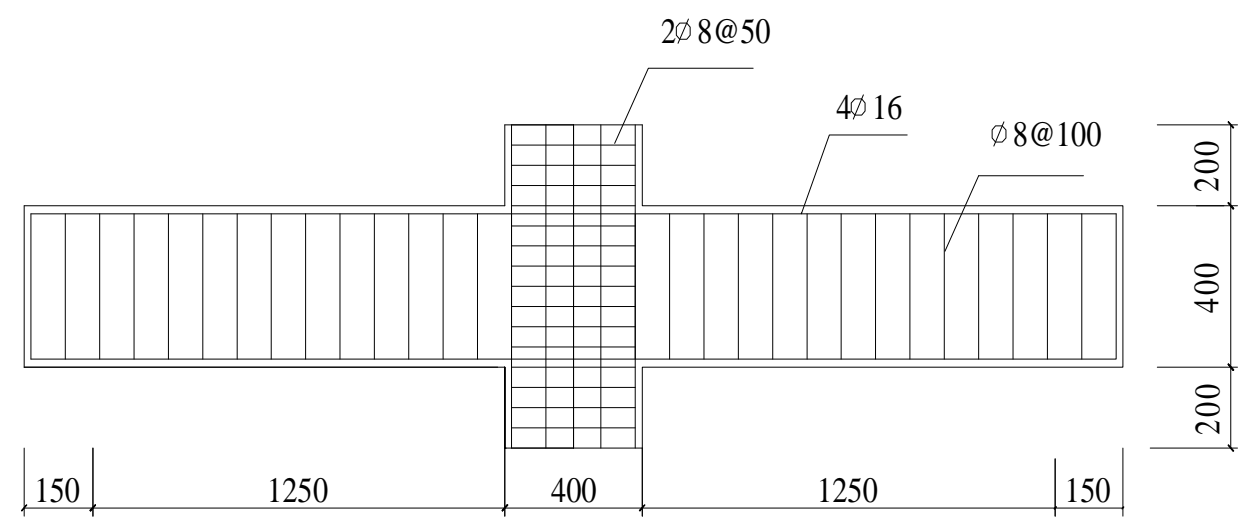

Fig. (1). Dimension and reinforcement arrangement.

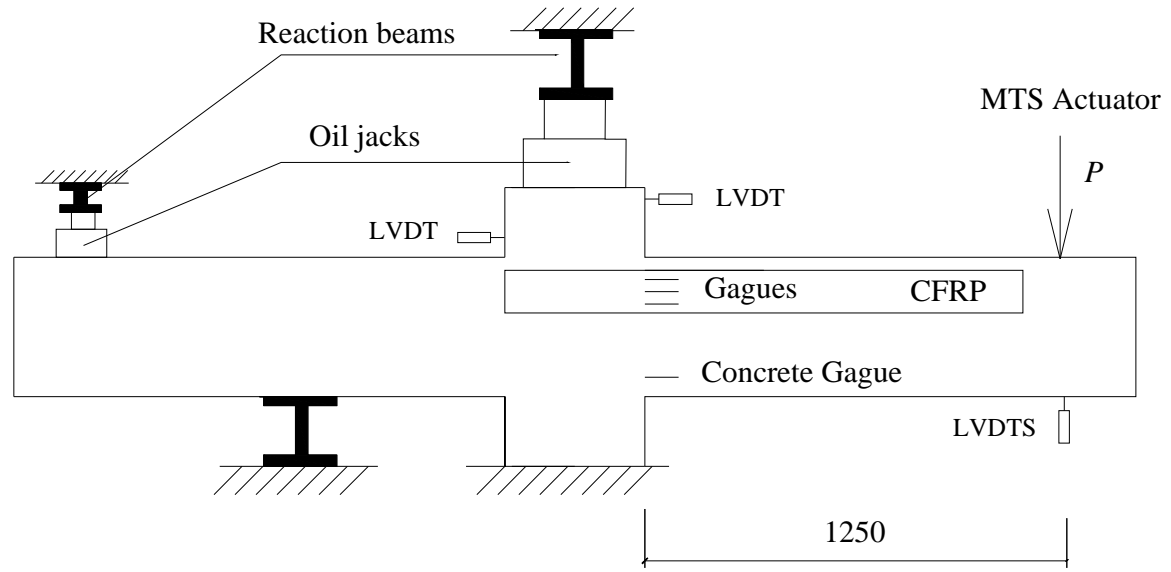

Fig. (2). Test setup and instrumentation arrangements.

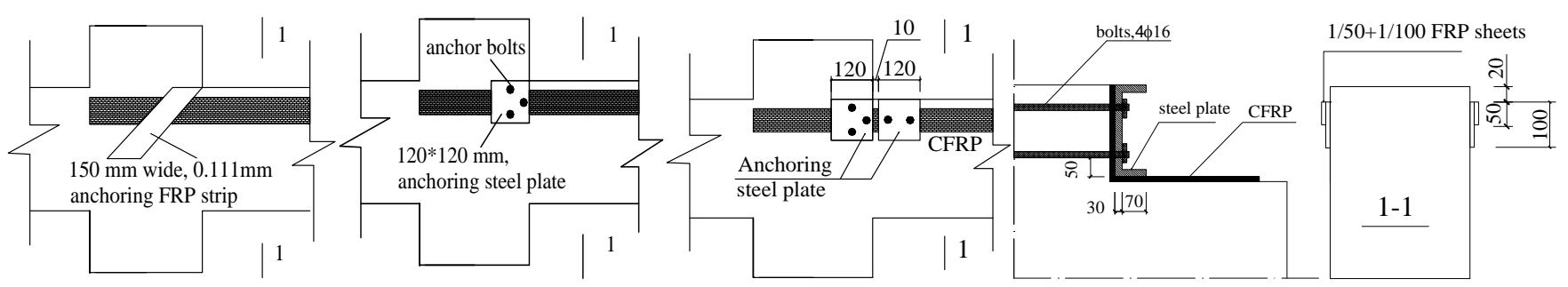

$\begin{array}{ll}\text { (a) 3F/6F (b) 3R1/6R1 (c)3R2/6R2 } & \text { (d) B10e/B20e (e) FRP sheets on 3R }\end{array}$

Fig. (3). Anchor method of CFRP laminates at the joint and amount of FRP sheets.

strengthened beams with rigid anchor of CFRP laminates is better than that of the beams with flexible anchor.

\section{ANALYSIS OF CHARACTERISTIC LOADS}

\section{First Crack Load}

It has been demonstrated that soffit bonding FRP laminates has little effect on the first crack load of the strengthened RC beams [5, 6]. However, as shown in Fig. (6), it is evident that side-bonding FRP laminates can significantly improve the first crack load of the strengthened beams. Compared to the first crack load of the control beam, the first crack load of beam 3F, 3R1, and 3R2 had an increase by $36 \%, 42 \%$, and $37 \%$, respectively. The first crack load of beam $6 \mathrm{~F}, 6 \mathrm{R} 1$, and $6 \mathrm{R} 2$ had a significantly increase by $79 \%, 79 \%$, and $77 \%$, respectively. The first
Table 1. Specimen

\begin{tabular}{|c|c|}
\hline Beam & CFRP Sheets \\
\hline \hline BC & Control beam \\
\hline $3 \mathrm{~F}$ & $2 / 75$ \\
\hline $3 \mathrm{R} 1$ & $1 / 50+1 / 100$ \\
\hline $3 \mathrm{R} 2$ & $1 / 50+1 / 100$ \\
\hline B10e & $1 / 300$ \\
\hline $6 \mathrm{~F}$ & $4 / 75$ \\
\hline $6 \mathrm{R} 1$ & $2 / 50+2 / 100$ \\
\hline $6 \mathrm{R} 2$ & $2 / 50+2 / 100$ \\
\hline B20e & $2 / 300$ \\
\hline
\end{tabular}


Table 2. Summary of Test Results $(\mathrm{kN})$

\begin{tabular}{|c|c|c|c|c|c|c|c|}
\hline Beam & $P_{\mathrm{cr}}{ }^{1}$ & $P_{y}$ & $P_{\mathrm{u}}$ & \multicolumn{3}{|c|}{$P_{\text {strengthened beam }} / P_{\mathrm{BC}}{ }^{2}$} & Failure Mode \\
\hline $\mathrm{BC}$ & 25.2 & 87.6 & 91.4 & - & - & - & flexural failure \\
\hline $3 \mathrm{~F}$ & 34.2 & 89.0 & 100.3 & 1.36 & 1.02 & 1.10 & anchor failure \\
\hline $3 \mathrm{R} 1$ & 35.8 & 90.7 & 105.2 & 1.42 & 1.04 & 1.15 & FRP debonding \\
\hline $3 \mathrm{R} 2$ & 34.5 & 91.0 & 104.2 & 1.37 & 1.04 & 1.14 & FRP debonding \\
\hline B10e & 25.5 & 104.3 & 113.9 & 1.01 & 1.19 & 1.25 & FRP debonding \\
\hline $6 \mathrm{~F}$ & 45.2 & 97.5 & 106.5 & 1.79 & 1.11 & 1.17 & anchor failure \\
\hline $6 \mathrm{R} 1$ & 45.1 & 90.2 & 104.2 & 1.79 & 1.03 & 1.14 & anchor failure \\
\hline $6 \mathrm{R} 2$ & 44.5 & 95.1 & 106.0 & 1.77 & 1.09 & 1.16 & anchor failure \\
\hline B20e & 25.9 & 107.5 & 123.0 & 1.03 & 1.23 & 1.35 & FRP debonding \\
\hline
\end{tabular}

1- $P_{\mathrm{cr}}, P_{\mathrm{y}}$, and $P_{\mathrm{u}}$ denote first crack load, first yield load, and ultimate load, respectively; 2-ratio of the characteristic load of the strengthenged beam to that of the control beam.
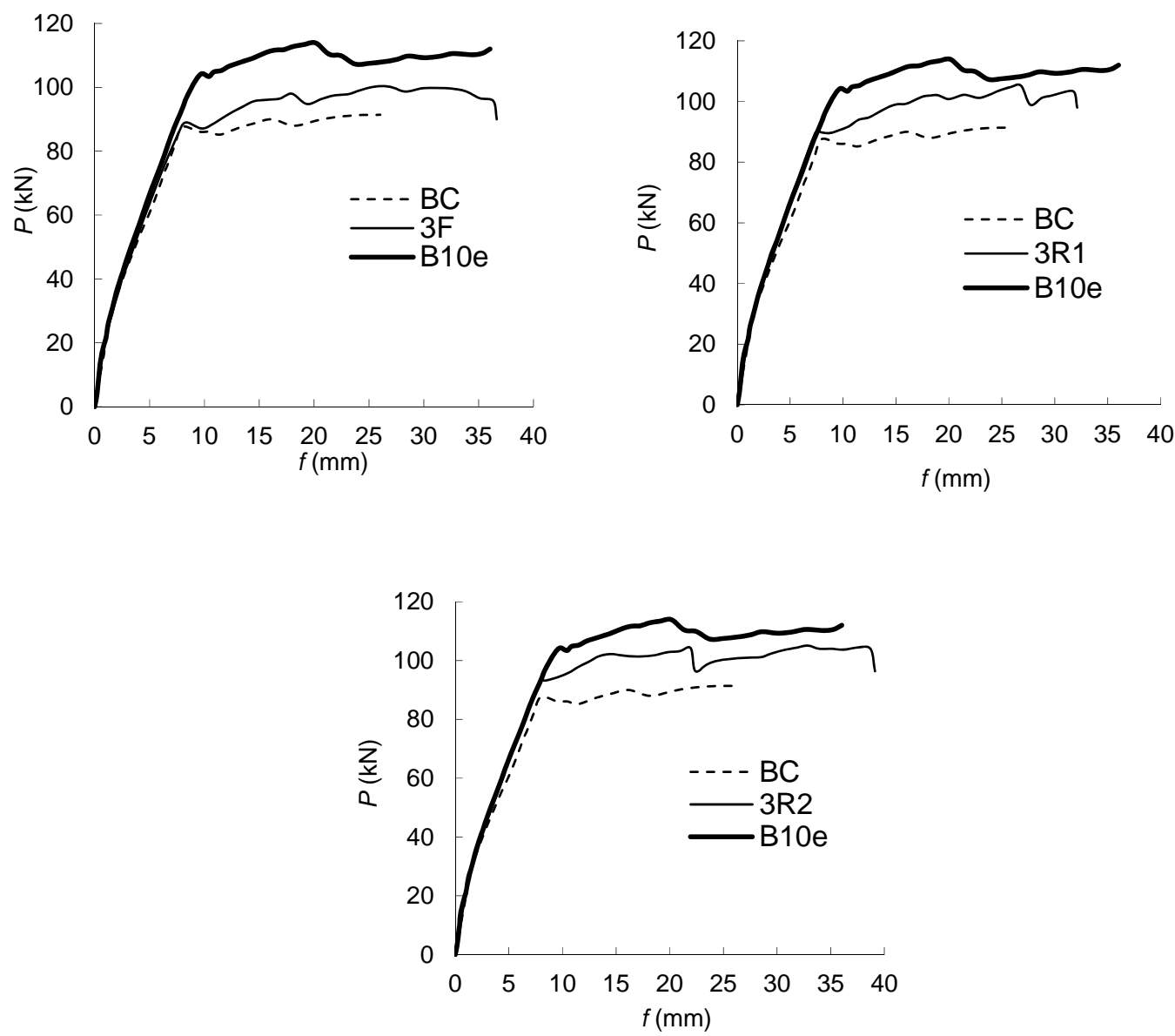

Fig. (4). Comparison of load-deflection relationships among beams BC, B10e, and 3F(3R1, 3R2).

crack load of Beam B10e and B20e is $25.5 \mathrm{kN}$ and $25.9 \mathrm{kN}$, respectively, which are almost the same with that of the control beam.

The present results verified that side-bonding FRP laminates could make a great contribution to confine concrete from premature cracking, this led to the first crack strength of RC beam improved significantly. According to the test results, there are three experimental phenomena can be employed to explain this result. Firstly, as shown in Fig. $(\mathbf{7 a}, \mathbf{b})$, the amount of cracks in the side-bonding beams is more than that in the control beam. These cracks spaced uniformly at about $100 \sim 150 \mathrm{~mm}$ which is less than that in 

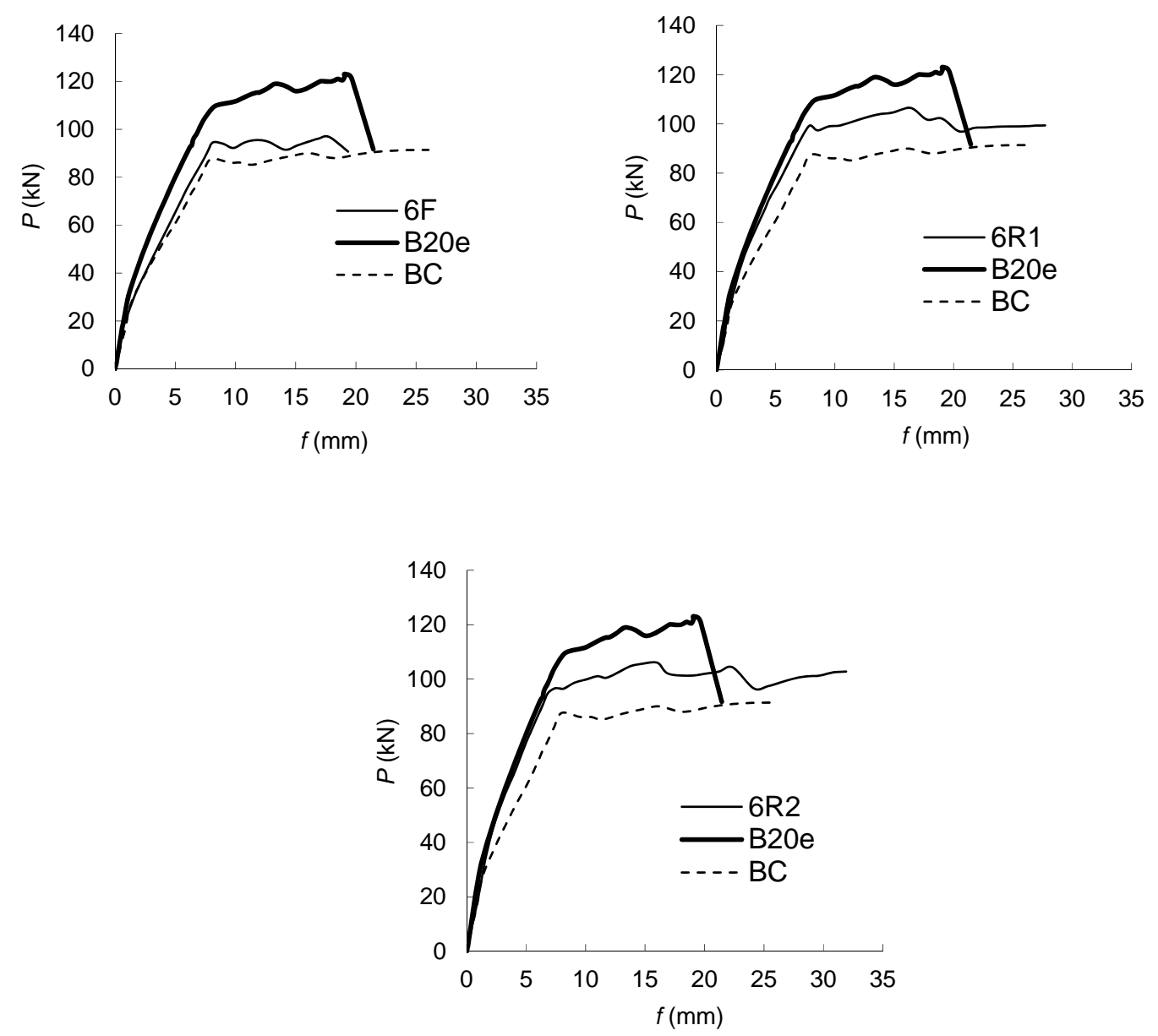

Fig. (5). Comparison of load-deflection relationships among beams BC, B20e, and 6F(6R1, 6R2).

the control beam about $200 \mathrm{~mm}$. Secondly, there are many smeared hairline cracks distributed on the soffit surface of the beam as shown in Fig. (7c, d). The two results indicate that tensile strain in concrete section distributes more uniformly in side-bonding FRP sheets RC beams. Thirdly, the strains in tensile rebar are within the range of $427 \sim 598 \mu \varepsilon$, that is, the stress of the tensile rebar is about $85 \sim 120 \mathrm{MPa}$ at the first crack load which is about 2 3 times of that of the control beam. All the results exhibit that the mechanical properties of side-bonding FRP sheets beams is like a sort of fiber reinforced concrete and external prestressed concrete.

\section{First Yield Load}

Compared with the first yield load of the control beam, the first yield load of beam 3F, 3R1, and 3R2 had an increase by $2 \%, 3 \%$, and $6 \%$, respectively, and the first yield load of beam $6 \mathrm{~F}, 6 \mathrm{R} 1$, and $6 \mathrm{R} 2$ had increase by $8 \%, 11 \%$, and $9 \%$, respectively. This result shows that the anchor methods have almost no effect on the first yield load of the strengthened beams, and this result shows explicitly in Fig. (8). Moreover, side-bonding FRP laminates has not significantly improved the first yield load of the strengthened beams. However, the first yield load of beam B10e and B20e had an increase by $19 \%$ and $23 \%$, respectively, which are much higher than that of the side-bonding beams.

\section{Ultimate Load}

Compared with the ultimate load of the control beam, the ultimate load of beam 3F, 3R1, and 3R2 had increase by $10 \%, 15 \%$, and $14 \%$, respectively, and the ultimate load of beam $6 \mathrm{~F}, 6 \mathrm{R} 1$, and $6 \mathrm{R} 2$ had increase by $6 \%, 17 \%$, and $16 \%$, respectively. The result shows that the ultimate load of

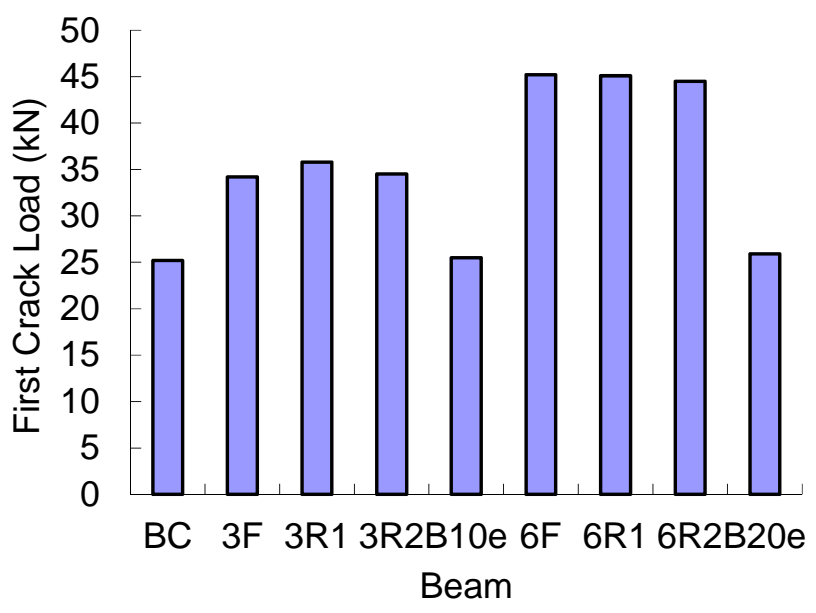

Fig. (6). Comparison of first crack loads of the test beams. 


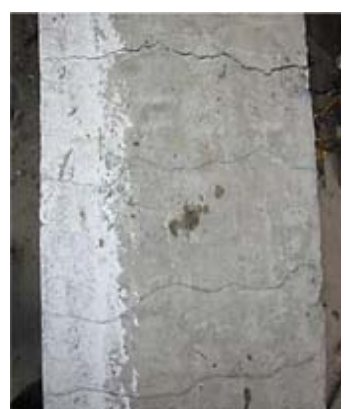

(a) $3 \mathbf{F}$

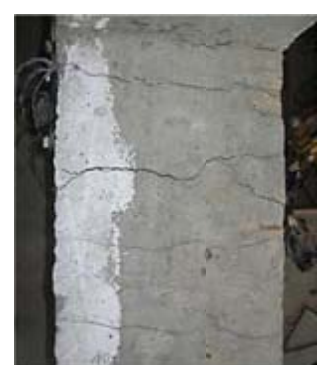

(b) 6R1

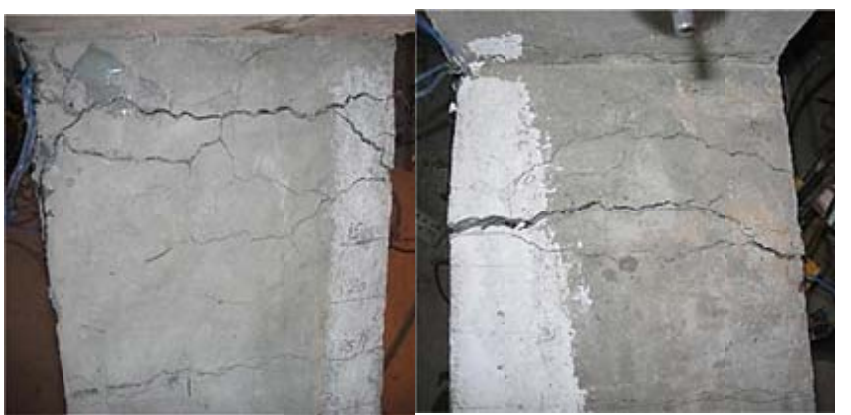

(c) $6 \mathrm{~F}$

(d) $6 \mathrm{R} 2$

Fig. (7). Cracking cheracteristics on beams 3F, 6R1, 6F, and 6R2.

the strengthened beams with flexible anchor is less than that of the ones with rigid anchor when the strengthening amount of FRP laminates is constant. Similar to the first yield load, side-bonding FRP laminates also had not significantly improved the ultimate load of the strengthened beams. However, the ultimate load of beam B10e and B20e had an increase by $25 \%$ and $35 \%$, respectively, which are two times of that of the side-bonding beams. Fig. (9) illustrates the comparison of the ultimate load of the tested beams.

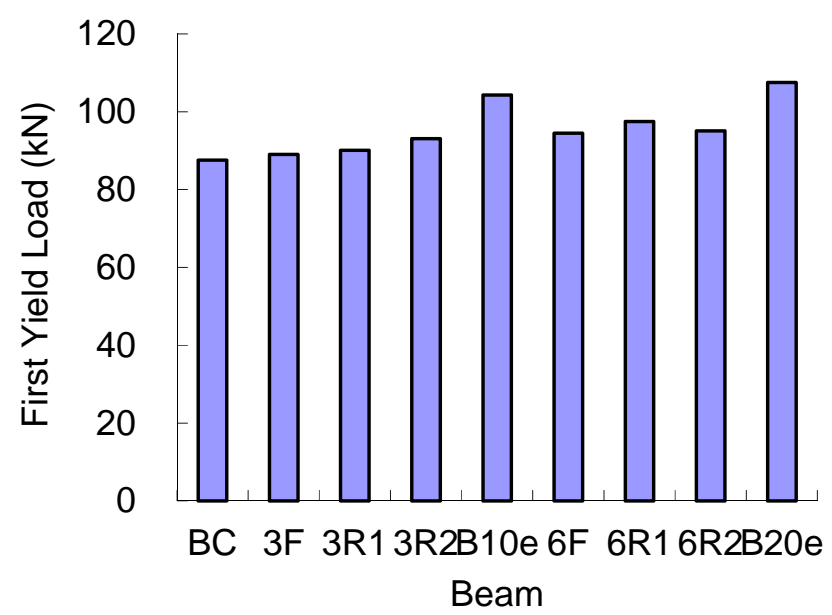

Fig. (8). Comparison of first yield loads of the test beams.

\section{ANALYSIS OF FLEXURAL STIFFNESS AND CRACK WIDTH}

\section{Analysis of Flexural Stiffness}

The deflection of the side-bonding beams is much bigger than that of the control beam at the first crack load. The flexural stiffness analysis of strengthened beams is summarized in Table 3. At first crack load, the deflection of the control beam is $1.50 \mathrm{~mm}$. The deflection of the sidebonding beams is in the range of 1.96-2.85 mm. Compared to the control beam, the deflection of beam $3 \mathrm{~F}, 3 \mathrm{R} 1$, and $3 \mathrm{R} 2$ had an increase by $53 \%, 32 \%$, and $31 \%$, respectively; the increase of beam 6F, 6R1, and 6R2 is $63 \%, 90 \%$, and $69 \%$, respectively. Therefore, side-bonding FRP laminates can significantly elongate the pre-crack stage of the strengthened beam.

At the precrack stage, the average of the flexural stiffness of beam 3F, 3R1, and 3R2 to that of the control beam is 1.04 with coefficient of variation 0.03 , the average of the flexural stiffness of beam $6 \mathrm{~F}, 6 \mathrm{R} 1$, and $6 \mathrm{R} 2$ to that of the control beam is 1.03 with coefficient of variation 0.07 . At the postcrack stage, the average of the flexural stiffness of beam $3 \mathrm{~F}$, $3 \mathrm{R} 1$, and $3 \mathrm{R} 2$ to that of the control beam is 0.98 with coefficient of variation 0.05 ; the average of the flexural stiffness of beam $6 \mathrm{~F}, 6 \mathrm{R} 1$, and $6 \mathrm{R} 2$ to that of the control beam is 1.07 with coefficient of variation 0.10 . At the postyield stage, the average of the flexural stiffness of beam $3 \mathrm{~F}$, $3 R 1$, and $3 R 2$ to that of the control beam is 3.64 ; the average of the flexural stiffness of beam $6 \mathrm{~F}, 6 \mathrm{R} 1$, and $6 \mathrm{R} 2$ to that of the control beam is 5.87 .

The average of the flexural stiffness of beam $3 \mathrm{~F}, 3 \mathrm{R} 1$, and $3 R 2$ is $17.54 \mathrm{kN} / \mathrm{mm}$ and the flexural stiffness of beam B10e is $18.21 \mathrm{kN} / \mathrm{mm}$ at precrack stage; $17.29 \mathrm{kN} / \mathrm{mm}$ and $16.50 \mathrm{kN} / \mathrm{mm}$ at the postcrack stage. The average of the flexural stiffness of beam $6 \mathrm{~F}, 6 \mathrm{R} 1$, and $6 \mathrm{R} 2$ is $9.41 \mathrm{kN} / \mathrm{mm}$ and the flexural stiffness of beam B20e is $9.54 \mathrm{kN} / \mathrm{mm}$ at precrack stage; $10.27 \mathrm{kN} / \mathrm{mm}$ and $10.89 \mathrm{kN} / \mathrm{mm}$ at the postcrack stage. This indicates that side-bonding and soffitbonding methods have the same effect on the flexural

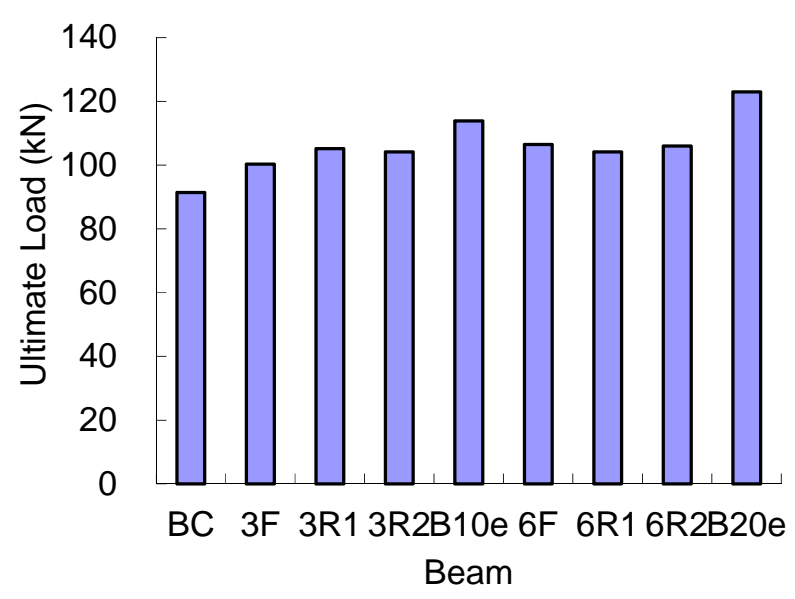

Fig. (9). Comparison of ultimate loads of the test beams. 
Table 3. Flexural Stiffness Analysis of Strengthened Beams

\begin{tabular}{|c|c|c|c|c|c|c|c|c|c|}
\hline \multirow{2}{*}{ Beam } & \multicolumn{3}{|c|}{ Deflection (mm) } & \multicolumn{3}{|c|}{ Stiffness(kN/mm) } & \multicolumn{3}{|c|}{ Stiffness Variation Compared to Control Beam } \\
\hline & $\delta_{\text {cr }}$ & $\delta_{\mathrm{y}}$ & $\delta_{\mathrm{u}}$ & $0-P_{\text {cr }}$ & $\boldsymbol{P}_{c r}-\boldsymbol{P}_{\mathrm{y}}$ & $P_{y}-P_{\mathrm{u}}$ & $0-P_{\text {cr }}$ & $\boldsymbol{P}_{c r}-\boldsymbol{P}_{\mathrm{y}}$ & $P_{y}-P_{\mathrm{u}}$ \\
\hline $\mathrm{BC}$ & 1.50 & 7.98 & 26.03 & 16.80 & 9.63 & 0.21 & 1.00 & 1.00 & 1.00 \\
\hline $3 \mathrm{~F}$ & 2.02 & 8.27 & 26.80 & 16.93 & 8.77 & 0.61 & 1.01 & 0.91 & 2.90 \\
\hline $3 \mathrm{R} 1$ & 1.98 & 7.47 & 26.82 & 18.08 & 10.00 & 0.75 & 1.08 & 1.04 & 3.56 \\
\hline $3 \mathrm{R} 2$ & 1.96 & 7.93 & 21.96 & 17.60 & 9.46 & 0.94 & 1.05 & 0.98 & 4.47 \\
\hline B10e & 1.40 & 9.86 & 20.15 & 18.21 & 9.31 & 0.93 & 1.08 & 0.97 & 4.43 \\
\hline $6 \mathrm{~F}$ & 2.45 & 7.93 & 17.56 & 18.45 & 9.54 & 0.93 & 1.10 & 0.99 & 4.44 \\
\hline 6R1 & 2.85 & 7.56 & 16.40 & 15.82 & 9.58 & 1.58 & 0.94 & 0.99 & 7.52 \\
\hline $6 \mathrm{R} 2$ & 2.53 & 6.86 & 16.05 & 17.59 & 11.69 & 1.19 & 1.05 & 1.21 & 5.63 \\
\hline B20e & 1.57 & 9.06 & 20.62 & 16.50 & 10.89 & 1.34 & 0.98 & 1.13 & 6.37 \\
\hline
\end{tabular}

stiffness of RC beams with same quantity of CFRP laminates before tension steel rebar yielding, this can be easily found in Figs. (10 and 11). As shown in Fig. (12), the flexural stiffness of RC beams can also be significantly improved by side-bonded CFRP laminates.

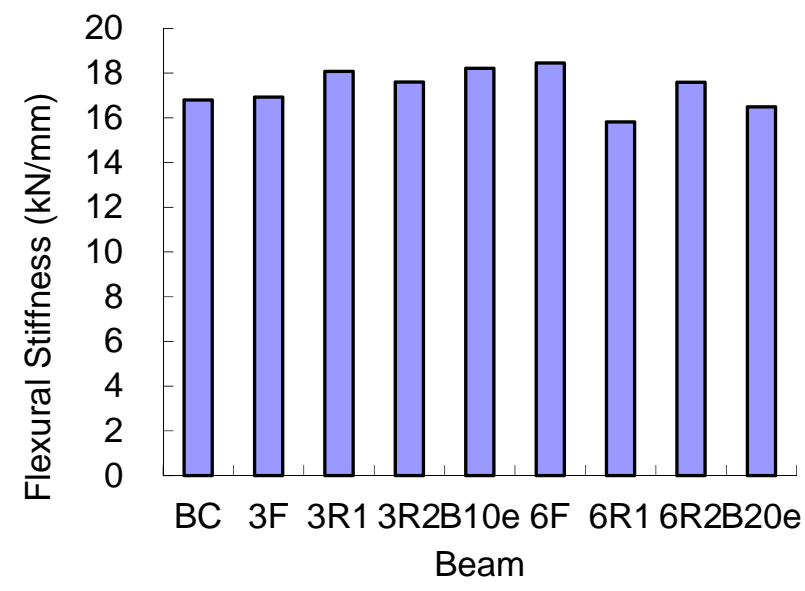

Fig. (10). Flexural stiffness of test beams at precrack stage.

\section{Analysis of Crack Width}

The maximum crack width of beam $6 \mathrm{~F}, 6 \mathrm{R} 1$, and $6 \mathrm{R} 2$ is $0.15,0.15$, and $0.20 \mathrm{~mm}$ at the first yield load, respectively, which is much smaller than that of the control beam, 0.30 $\mathrm{mm}$; B10e $0.35 \mathrm{~mm}$; B20e $0.25 \mathrm{~mm}$. Furthermore, at the load $91.4 \mathrm{kN}$ which is the ultimate load of the control beam, the maximum crack width of these beams is only $0.1-0.2$ $\mathrm{mm}$, but the crack width of the control beam is $3.4 \mathrm{~mm}$, and there are two cracks exceed $3.0 \mathrm{~mm}$. This indicates that sidebonding FRP laminate can effectively decrease the crack width of the strengthened beams.

\section{Analysis on Anchor Program}

In the flexible anchored beams $3 \mathrm{~F}$ and $6 \mathrm{~F}$, the tensile stress in the side-bonded FRP laminates at the critical section increased rapidly after concrete cracking. As a result, the stress in the anchoring FRP laminates also increased. Soon after the tension rebar yield, the anchoring FRP laminates

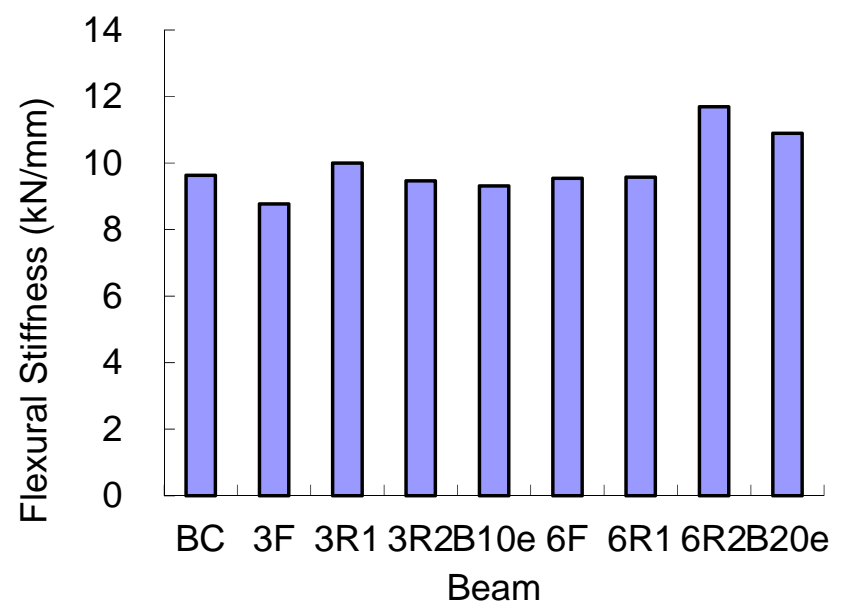

Fig. (11). Flexural stiffness of test beams at postcrack stage.

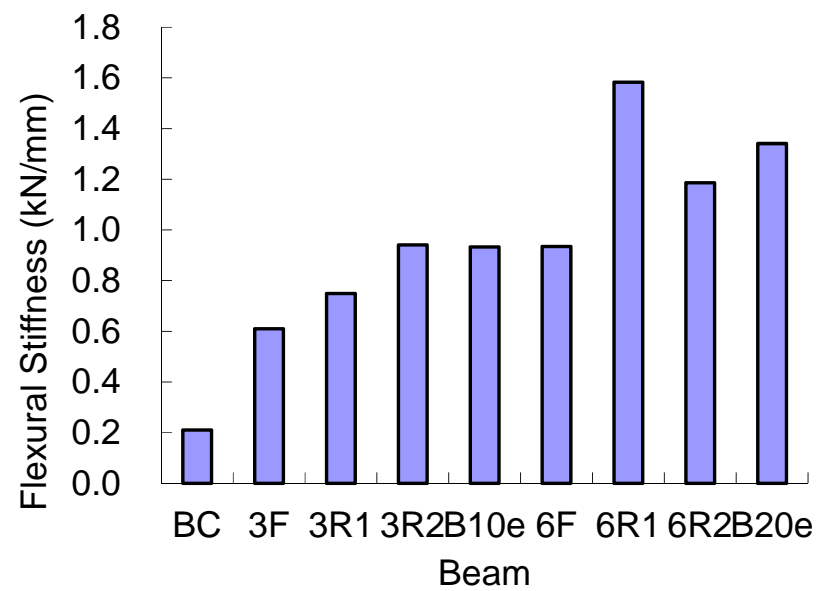

Fig. (12). Flexural stiffness of test beams at postyield stage. 
were tore into strips gradually, and then the side-bonded FRP laminates were out of work at the post yield stage. In the rigid anchor beams $3 R$ and $6 R$, the main failure mode was concrete crush tensioned by the anchor bolts. According to the analytical results of the characteristic loads of the test beams as shown in Table 2 and Fig. (5), it can be concluded that the rigid anchor program is better than the flexible anchor program.

\section{CONCLUSIONS}

This paper carried out an experimental study on the flexural performance of RC beams side-bonded and soffitbonded FRP laminate. The following conclusions can be drawn:

1) side-bonded and soffit-bonded CFRP laminates have almost the same effect on the flexural stiffness of RC beams strengthened by same quantity of CFRP laminates before tension rebar yielding. However, side-bonded CFRP laminates can affect crack width and crack pattern of the strengthened beams, and the pre-crack stage of RC beam side-bonded CFRP laminates extended remarkably.

2) side-bonded CFRP laminates can also improve the flexural behavior of $\mathrm{RC}$ beams, and the first crack loads of RC beams side-bonded CFRP laminates are much higher than that of $\mathrm{RC}$ beams soffit-bonded CFRP laminates. Like fiber reinforced concrete, side-bonded CFRP laminates can significantly improve the first crack strength of RC beams.

3) the first yielding load and the ultimate load of RC beam side-bonded CFRP laminates cannot be improved significantly as that of soffit-bonded CFRP laminates beams. This indicates that it would be best not to use side-bonded FRP laminates to improve the ultimate flexural capacity of RC beam.

\section{CONFLICT OF INTEREST}

Declared none.

\section{ACKNOWLEDGEMENTS}

The research program discussed in this paper was funded by the Ministry of Housing and Rural-Urban Development of PRC (2009-K2-39) and the National High Technology Research and Development Program of China (863 Program, No. 2007AA04Z437).

\section{REFERENCES}

[1] J. Zhang, L. Yue, Z. Lv, and M. Gu,“ Experimental study on the behavior of the strengthened RC beam side-bonded with CFRP sheets", J. Dongnan Univ.(Science edition), vol. 32, no. 2, pp. 760765, October 2002. (in Chinese)

[2] D.J. Oehlers, S.M. Park, and M.S. Mohamed Ali, "A structural engineering approach to adhesive bonding longitudinal plates to RC beams and slabs", Compos. Part A: Appl. Sci. Manuf., vol. 34 no. 9, pp. 887-897, September 2003.

[3] Mohamed Ali, M.S., D.J. Oehlers, and S.-M. Park, "Comparison between FRP and steel plating of reinforced concrete beams", Compos. Part A: Appl. Sci. Manuf., vol. 32, no. 9, pp. 1319-1328, September 2001.

[4] China association for engineering construction standardization, "Technical specification for strengthening concrete structures with carbon fiber reiforced polymer laminate", China planning press, Beijing, 2003. (in Chinese)

[5] G. Li, A. Zhang, and W. Jin, " Study on flexural performance of cracked RC beams retrofitted with CFRP sheets", J. Zhejiang Univ. (science editon), vol. 39, no. 1, pp. 73-78, January 2005. (in Chinese)

[6] A.H. Zhang, W.L. JIN, and G.B. Li, "Behavior of preloaded RC beams strengthened with CFRP laminates", J. Zhejiang Univ.: SCIENCE A, vol. 7, no. 1, pp. 436-444, March 2006. 